\title{
Alteration of the critical arteriovenous oxygen saturation relationship by sustained afterload reduction after the Norwood procedure
}

\author{
George M. Hoffman, MD ${ }^{a, b, e, f}$ \\ James S. Tweddell, $M^{\mathrm{c}, e, f}$ \\ Nancy S. Ghanayem, MD ${ }^{\mathrm{b}, \mathrm{e}, \mathrm{f}}$ \\ Kathy A. Mussatto, BSN ${ }^{\mathrm{e}}$ \\ Eckehard A. Stuth, MDa,e,f \\ Robert D. B. Jaquis, $M D^{c, e, f}$ \\ Stuart Berger, $M D^{d, e, f}$
}

From the Departments of Anesthesiology,
Pediatric Critical Care Medicine, ${ }^{\mathrm{b}}$ Cardio-
thoracic Surgery, ${ }^{\mathrm{c}}$ and Pediatric Cardiolo-
gy, ${ }^{\mathrm{d}}$ Children's Hospital of Wisconsin, ${ }^{\mathrm{e}}$ and
the Medical College of Wisconsin, ${ }^{\mathrm{f}}$ Mil-
waukee, Wis.

Presented in part at the annual meeting of the American Society of Anesthesiologists, New Orleans, La, October 2001.

Received for publication March 18, 2003; revisions requested April 22, 2003; revisions received May 19, 2003; accepted for publication June 18, 2003.

Address for reprints: George Hoffman, MD, Pediatric Anesthesiology and Critical Care Medicine, Children's Hospital of Wisconsin, \#735, 9000 West Wisconsin Ave, Milwaukee, WI 53226 (E-mail: ghoffman @ mcw.edu).

J Thorac Cardiovasc Surg 2004;127:738-45

$0022-5223 / \$ 30.00$

Copyright (C) 2004 by The American Association for Thoracic Surgery

doi:10.1016/S0022-5223(03)01315-1
Objectives: Hemodynamic vulnerability after the Norwood procedure for hypoplastic left heart syndrome results from impaired myocardial function, and critical inefficiency of parallel circulation. Traditional management strategies have attempted to optimize circulatory efficiency by using arterial oxygen saturation $\left(\mathrm{SaO}_{2}\right)$ as an index of pulmonary/systemic flow balance, attempting to maintain $\mathrm{SaO}_{2}$ within a theoretically optimal critical range of $75 \%$ to $80 \%$. This optimal range of $\mathrm{SaO}_{2}$ has not been verified clinically, and strategies targeting $\mathrm{SaO}_{2}$ may be limited by the fact that $\mathrm{SaO}_{2}$ is a poor predictor of systemic oxygen delivery. We have previously reported higher venous saturation $\left(\mathrm{SvO}_{2}\right)$, lower arteriovenous oxygen content difference, lower systemic vascular resistance, lower pulmonary/systemic flow ratio, and improved survival with the perioperative use of phenoxybenzamine and continuous monitoring of $\mathrm{SvO}_{2}$. In this investigation, we tested the hypothesis that intense afterload reduction with phenoxybenzamine would modify the $\mathrm{SvO}_{2}-\mathrm{SaO}_{2}$ relationship by preventing deterioration of systemic oxygen delivery at high $\mathrm{SaO}_{2}$.

Methods: Seventy-one consecutive neonates undergoing the Norwood procedure with and without phenoxybenzamine were studied. Perioperative hemodynamic management targeted $\mathrm{SvO}_{2}$ greater than 50\%. Hemodynamic data were prospectively acquired for 48 hours postoperatively and analyzed to assess the effect of phenoxybenzamine on the relationship between $\mathrm{SaO}_{2}$ and $\mathrm{SvO}_{2}$ and other hemodynamic indices. Sixty-two patients received phenoxybenzamine $0.25 \mathrm{mg} / \mathrm{kg}$ on cardiopulmonary bypass; 9 who did not served as controls.

Results: In control patients, $\mathrm{SvO}_{2}$ peaked at an $\mathrm{SaO}_{2}$ of $77 \%$, with reduced $\mathrm{SvO}_{2}$ at $\mathrm{SaO}_{2}>85 \%$ and $\mathrm{SaO}_{2}<70 \%(P<.01)$, while arteriovenous oxygen content difference increased with $\mathrm{SaO}_{2}$ greater than $80 \%(P<.001)$. In patients receiving phenoxybenzamine, the $\mathrm{SvO}_{2}$ increased linearly with $\mathrm{SaO}_{2}$ greater than $65 \%(P<$ $.001)$, and arteriovenous oxygen content difference was constant at all $\mathrm{SaO}_{2}(P=$ ns). The $\mathrm{SvO}_{2}$ was higher, and the arteriovenous oxygen content difference lower, across the whole $\mathrm{SaO}_{2}$ range with phenoxybenzamine $(P<.0001)$.

Conclusions: A critical range of $\mathrm{SaO}_{2}$ for optimizing systemic oxygen delivery was confirmed in control patients, and was effectively eliminated by phenoxybenzamine, specifically by eliminating the systemic hypoperfusion associated with high $\mathrm{SaO}_{2}$. This effect allows higher $\mathrm{SaO}_{2}$ to be included in a rational hemodynamic strategy to improve systemic oxygen delivery in the early postoperative management of patients receiving intense afterload reduction with phenoxybenzamine. The predictability of $\mathrm{SvO}_{2}$ from $\mathrm{SaO}_{2}$ is low in both groups, emphasizing the importance of $\mathrm{SvO}_{2}$ measurement in these patients. 


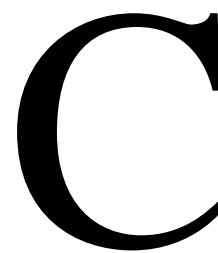

ardiogenic shock remains a major cause of morbidity after the Norwood procedure. Following the Norwood procedure, the neonate has a unique convergence of physiologic vulnerabilities: myocardial dysfunction after ischemia, reperfusion, and cardiopulmonary bypass (CPB), potential limitations of a morphologically right ventricle, potential aorta-coronary flow limitation, and intrinsic inefficiency of parallel circulation. ${ }^{1,2}$ Management of the interactions of these multiple vulnerabilities in the postoperative period is complex and has been approached both theoretically via circulatory models and empirically by direct measurement of additional physiologic parameters such as systemic venous saturation $\left(\mathrm{SvO}_{2}\right)^{1,3,4}$ in an attempt to avoid or detect hemodynamic deterioration before cardiovascular collapse.

Several models with differing assumptions about complex univentricular circulation have been developed to guide management when clinical data are incomplete. Norwood and colleagues $^{1,2,5}$ have argued that maintenance of arterial saturation $\left(\mathrm{SaO}_{2}\right)$ in the $75 \%$ to $80 \%$ range would optimize circulatory efficiency with a resulting $\mathrm{SvO}_{2}$ of $50 \%$ to $60 \%$ and pulmonary/systemic flow ratio (Qp/Qs) near 1.0. This management strategy is based largely on circulatory modeling with a constant arteriovenous oxygen content difference, but highly variable Qp/Qs and therefore $\mathrm{SaO}_{2}{ }^{1,2,5,6}$ Alternatively, the $\mathrm{SaO}_{2}-\mathrm{SvO}_{2}$ relationship has been modeled at constant total cardiac output, with variable Qp/Qs and systemic flow, also resulting in a narrow optimum range of $\mathrm{SaO}_{2}$ to maximize $\mathrm{SvO}_{2}$ or systemic oxygen delivery. ${ }^{6}$ In either case, the circulatory models predict a critical range of $\mathrm{SaO}_{2}$ for optimal circulatory efficiency, but the exact target $\mathrm{SaO}_{2}$ remains dependent on other parameters such as oxygen consumption $\left(\mathrm{VO}_{2}\right)$, cardiac output, and hemoglobin, as well as knowledge of Qp/Qs to fully resolve the resulting $\mathrm{SvO}_{2} \cdot{ }^{6}$ Strategies to balance the circulation have typically relied on manipulation of medical gases to raise pulmonary vascular resistance (PVR) and restrict $\mathrm{SaO}_{2}$ to the target range of $75 \%$ to $80 \%$. $^{1,2,5,7-10}$

In a less restrictive model assuming complete systemic and pulmonary mixing, and permitting variability in both Qp/Qs and total cardiac output, we demonstrated a wide range of $\mathrm{SvO}_{2}$ at any $\mathrm{SaO}_{2}$, and the essential lack of predictability of $\mathrm{SvO}_{2}$ from $\mathrm{SaO}_{2}{ }^{11}$ This theoretical inadequacy of $\mathrm{SaO}_{2}$ as a predictor of $\mathrm{SvO}_{2}$, the intrinsic contradictions and complexities of management strategies which rely on $\mathrm{SaO}_{2}$ limitation as a means of maximizing oxygen delivery, and less than optimal outcomes using approaches based on prediction of $\mathrm{SvO}_{2}$ from $\mathrm{SaO}_{2}$, motivated us to search for a better management method. Direct, continuous measurement of $\mathrm{SvO}_{2}$ allowed the detection of critical reductions in systemic oxygen delivery and provided additional data to more closely estimate Qp/Qs and guide sub- sequent intervention. ${ }^{3,12}$ We observed wide variability in $\mathrm{SvO}_{2}$ despite maintenance of $\mathrm{SaO}_{2}$ in the traditional target range, ${ }^{12,13}$ emphasizing the dynamic relationships between reduction in systemic oxygen delivery, reflex elevation in systemic vascular resistance (SVR), systemic-pulmonary flow tradeoff, and further reductions in systemic perfusion with systemic vasoconstriction, which, if unchecked, would lead to overt failure of systemic perfusion.

We hypothesized that the relevance of increases in SVR as a cause of instability after the Norwood procedure could be confirmed by examination of the relationship between $\mathrm{SaO}_{2}$ and $\mathrm{SvO}_{2}$ for evidence of deterioration of systemic oxygenation at higher $\mathrm{SaO}_{2}$. In this investigation, we analyzed our prospectively collected physiologic database to attempt to confirm the existence of a critical $\mathrm{SaO}_{2}$ range to maximize $\mathrm{SvO}_{2}$, and to test the hypothesis that this relationship would be altered by intense afterload reduction with phenoxybenzamine.

\section{Materials and Methods}

\section{Patient Population and Management Strategy}

All patients undergoing the Norwood procedure for hypoplastic left heart syndrome from July 1996 to July 2000 were included in this study. After appropriate preoperative stabilization, all patients underwent surgical palliation consisting of anastomosis of the pulmonary artery to the ascending aorta combined with augmentation of the ascending aorta, transverse arch, and proximal descending aorta with pulmonary homograft, placement of a systemic-pulmonary artery shunt (3.0-4.5 mm), and creation of a nonrestrictive atrial septal defect. ${ }^{12}$ This procedure was performed with synthetic opioid-based perioperative anesthesia, ${ }^{14}$ hypothermic CPB with $\mathrm{pH}$-stat blood gas management to facilitate cooling to a temperature of $26^{\circ} \mathrm{C}, \alpha$-stat management before and after circulatory arrest at $16^{\circ} \mathrm{C}$ to $18^{\circ} \mathrm{C}$, and modified ultrafiltration. On initiation of $\mathrm{CPB}$, phenoxybenzamine $0.25 \mathrm{mg} / \mathrm{kg}$ was administered to 62 of 71 infants according to a prospective nonrandomized surgeon-directed protocol with Food and Drug Administration and institutional review board approval and parental informed consent. During rewarming, all patients received milrinone $50 \mu \cdot \mathrm{kg}^{-1}$ followed by infusions of milrinone at $0.5 \mu \cdot \mathrm{kg}^{-1} \cdot \min ^{-1}$ and dopamine at $3 \mu \cdot \mathrm{kg}^{-1} \cdot \mathrm{min}^{-1}$. Oximetric catheters (4F OxyCath, Abbott Laboratories, N Chicago, Ill) were surgically placed in the superior vena cava (SVC) to allow continuous monitoring of $\mathrm{SvO}_{2}$. Before separation from CPB, infusions of nitroprusside or norepinephrine were titrated to achieve an approximate SVR index of 12 Wood units (mean arterial pressure of $40 \mathrm{~mm} \mathrm{Hg}$ at CPB flow index of $3.2 \mathrm{~L} / \mathrm{m}^{2} / \mathrm{min}$ ), and epinephrine was added for additional inotropic support if necessary. Patients were transported to the pediatric intensive care unit (ICU) after hemostasis for postoperative management, which included routine delayed sternal closure.

Postoperative management targets included mean arterial blood pressure (MAP) greater than $45 \mathrm{~mm} \mathrm{Hg}, \mathrm{SvO}_{2}$ greater than $50 \%$, $\mathrm{SaO}_{2} 70 \%$ to $85 \%$, and clinical evidence of end-organ function (urine output of at least $1 \mathrm{~mL} \cdot \mathrm{kg}^{-1} \cdot \mathrm{h}^{-1}$, biochemical evidence of adequate gluconeogenesis, and behavioral responses after withdrawal of neuromuscular blockade). Systemic diastolic pressure 
TABLE 1. Patient demographics

\begin{tabular}{lcc}
\hline & $\begin{array}{c}\text { Control } \\
\text { (n = 9) }\end{array}$ & $\begin{array}{c}\text { Phenoxybenzamine } \\
\text { (n = 62) }\end{array}$ \\
\hline Age (d) & $7.2 \pm 6.4$ & $6.0 \pm 3.3$ \\
Weight (kg) & $3.7 \pm 0.5$ & $3.2 \pm 0.6$ \\
Preoperative mechanical & $6 / 9(67 \%)$ & $46 / 62(75 \%)$ \\
$\quad$ ventilation & & \\
Preoperative inotropic support & $4 / 9(44 \%)$ & $29 / 62(47 \%)$ \\
Aortic atresia & $4 / 9(44 \%)$ & $35 / 62(56 \%)$ \\
AAO diameter (mm) & $3.33 \pm 0.88$ & $3.11 \pm 1.31$ \\
CPB time (min) & $157 \pm 70$ & $125 \pm 52$ \\
DHCA time (min) & $64 \pm 13$ & $62 \pm 14$ \\
Shunt diameter (mm) & $3.94 \pm 0.47$ & $3.67 \pm 0.36$ \\
Normallized shunt size & $3.50 \pm 0.83$ & $3.43 \pm 0.47$ \\
$\quad$ (mm $\left.{ }^{2} / \mathrm{kg}\right)$ & $1 / 9(11 \%)$ & $1 / 62(2 \%)$ \\
ECMO & & \\
Death & & \\
$\quad$ Early & & \\
$\quad$ Late & $0 / 9(0 \%)$ & $3 / 62(5 \%)$ \\
\end{tabular}

Data are expressed as mean \pm standard deviation or $\mathrm{N}$ and \%. No significant differences between groups exist for demographic, preoperative, and operative factors. $A A O$, Ascending aortic diameter; $C P B$, cardiopulmonary bypass; $D H C A$, deep hypothermic circulatory arrest; ECMO, extracorporeal membrane oxygenation.

was not specifically targeted unless electrophysiologic evidence of ischemia was present with continuous ST analysis (Solar 3000, Marquette Electronics Inc, Milwaukee, Wis). All patients received continuous fentanyl infusions at 5 to $10 \mu \mathrm{g} \cdot \mathrm{kg}^{-1} \cdot \mathrm{h}^{-1}$, and neuromuscular blockade was maintained by vecuronium infusion until postoperative day 1 . A normothermic environment was maintained with servo controlled warmers (Ohio Infant Warmer System, Ohmeda Inc, Columbia, Md). Ventilator settings were adjusted to maintain arterial normocapnia $\left(\mathrm{PaCO}_{2} 35\right.$ to $\left.45 \mathrm{~mm} \mathrm{Hg}\right)$ with inflating pressures of 24 to $28 \mathrm{~cm} \mathrm{H}_{2} \mathrm{O}$, positive end-expiratory pressure of 4 to $5 \mathrm{~cm} \mathrm{H}_{2} \mathrm{O}$, and an $\mathrm{FIO}_{2}$ of 0.3 to 1.0 to assure fully saturated pulmonary capillary blood. ${ }^{15}$ Specifically, room air was not used as a ventilating gas, and $\mathrm{FIO}_{2}$ was adjusted to maximize $\mathrm{SvO}_{2}$. Low $\mathrm{SvO}_{2}$ (40\% or less) with Qp/Qs near 2.0 or greater was addressed by attempts to lower SVR with additional analgesia or sedation, nitroprusside, or, in patients who had received phenoxybenzamine on $\mathrm{CPB}$, initiation of a phenoxybenzamine infusion $\left(0.25 \mathrm{mg} / \mathrm{kg}\right.$ per day or $\left.10 \mu \mathrm{g} \cdot \mathrm{kg}^{-1} \cdot \mathrm{h}^{-1}\right)$. A low $\mathrm{SvO}_{2}$ with Qp/Qs near 1.0 was addressed by transfusion of red cells to achieve a hematocrit value in the $45 \%$ to $50 \%$ range, and additional inotropic support when necessary.

\section{Monitoring and Data Collection}

A prospective perioperative database for all patients undergoing the Norwood repair for hypoplastic left heart syndrome since July 1996 was maintained for demographic, surgical, and 48-hour postoperative hemodynamic and laboratory data. Physiologic parameters included invasive arterial (MAP) and atrial pressures (RAP), arterial saturation (N-200, Nellcor, Haywood, Calif), inspired oxygen and end-tidal carbon dioxide tension, and oximetric $\mathrm{SvO}_{2}$ from the SVC as an approximation of mixed venous saturation. ${ }^{1,16}$

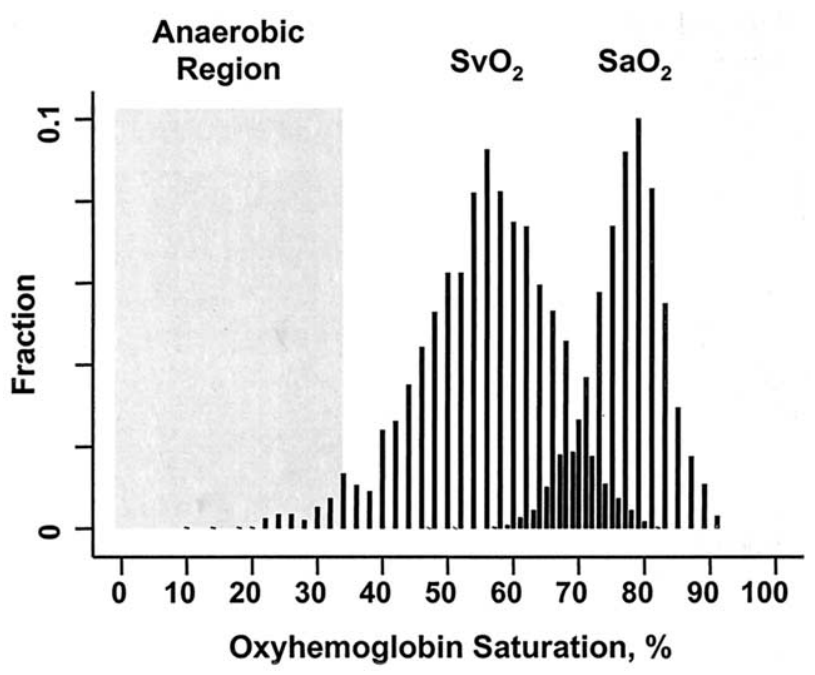

Figure 1. The distribution of arterial and venous saturation values found over first 48 hours in all patients is shown. $\mathrm{SaO}_{2}$ (mean 77.9, SD 5.5) was more tightly controlled than $\mathrm{SvO}_{2}$ (mean 54.9, SD 10.7). Approximately $26 \%$ of the measured values for $\mathrm{SvO}_{2}$ were less than thetarget of $50 \%$, and $1.8 \%$ were less than the anaerobic threshold of $30 \%$ (shaded area).

These parameters were continuously displayed, digitally acquired, and averaged using either a dedicated personal computer-based monitoring cart (DAP-102; Microstar Labs, Belleview, Wash; DasyLab, DasyTec GmBH, Concord, NH) or a multichannel clinical information system (Marquette Solar). Arterial and venous blood gases and co-oximetry (ABL, Radiometer, Copenhagen, Denmark) were obtained at clinically appropriate intervals. The physiologic parameters, laboratory data, ventilator parameters, and medication infusion rates were recorded hourly for the first 48 postoperative hours with a standardized, prospective data record.

From measurements of $\mathrm{SaO}_{2}, \mathrm{SvO}_{2}, \mathrm{MAP}$, RAP, and hemoglobin concentration, hemodynamic and oxygen transport indices were derived according to standard formulas. These derived parameters included arteriovenous $\mathrm{O}_{2}$ difference in saturation $(\Delta \mathrm{Sa}-$ $\left.\mathrm{vO}_{2}\right)$ and content $\left(\Delta \mathrm{Ca}-\mathrm{vO}_{2}\right)$, as well as oxygen extraction ratio $\left(\mathrm{O}_{2} \mathrm{ER},\left[\Delta \mathrm{Sa}-\mathrm{vO}_{2}\right] / \mathrm{SaO}_{2}\right)$, and oxygen excess factor $\left(\Omega \mathrm{SaO}_{2} /\right.$ $\left.\left[\Delta \mathrm{Sa}-\mathrm{vO}_{2}\right]\right)$, both flow-independent indices of systemic oxygen status. Pulmonary/systemic flow ratio (Qp/Qs) was calculated from $\mathrm{SaO}_{2}$ and $\mathrm{SvO}_{2}$ using an assumed pulmonary capillary saturation of $97 \%$. $3,4,12,15$ Additional parameters derived from an assumed oxygen consumption of $160 \mathrm{~mL} \cdot \mathrm{min}^{-1} \cdot \mathrm{m}^{-2} 13,17-19$ included pulmonary blood flow (Qp), systemic blood flow (Qs), systemic oxygen delivery $\left(\mathrm{DO}_{2}\right)$, systemic vascular resistance index (SVRI), and total pulmonary vascular resistance index (PVRI).

\section{Statistical Analysis}

Data were summarized as mean \pm standard deviation (SD) when continuous, or number and percent when discrete. Oximetric data were excluded during extracorporeal membrane oxygenator (ECMO) support and when the $\mathrm{SaO}_{2}-\mathrm{SvO}_{2}$ difference was less than $8 \% .{ }^{13}$ Exploratory analysis of the $\mathrm{SvO}_{2}-\mathrm{SaO}_{2}$ relationship was performed by locally weighted regression, ${ }^{20}$ and fractional 


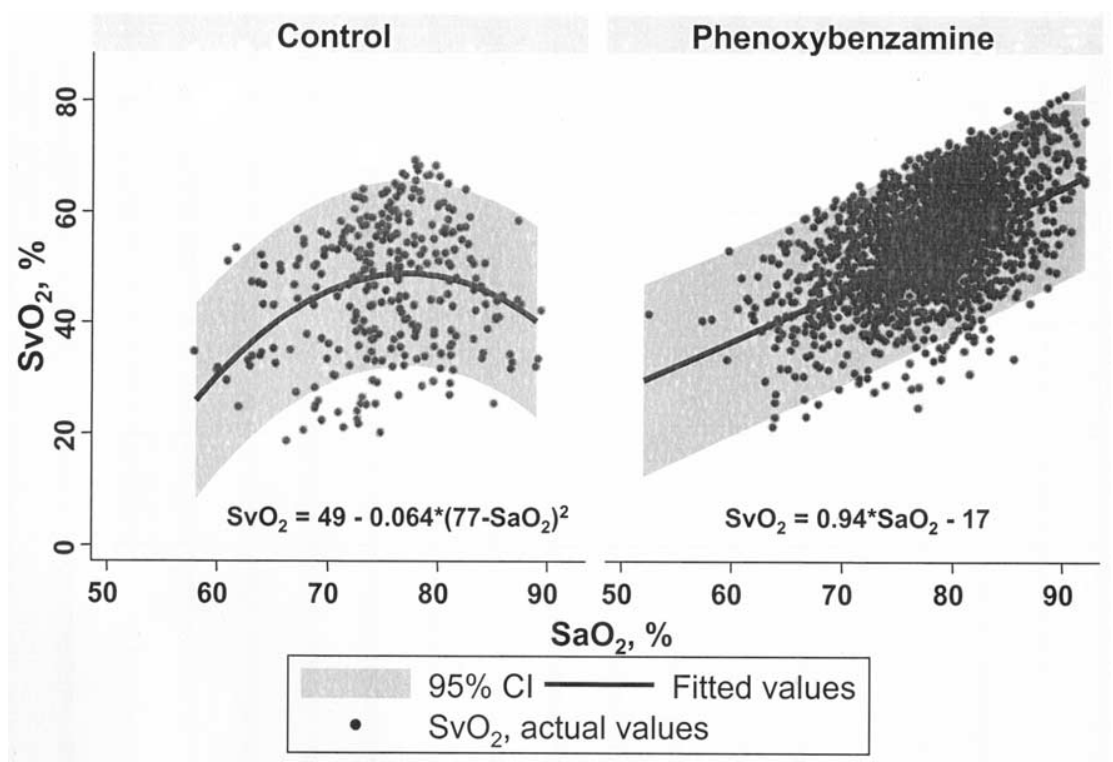

Figure 2. The relationship between $\mathrm{SvO}_{2}$ and $\mathrm{SaO}_{2}$ over the first 48 hours is shown for patients managed with and without phenoxybenzamine. Hourly data and fitted fractional polynomial regression lines with $95 \%$ prediction intervals are shown for the control (left panel, $n=307$ ) and phenoxybenzamine (right panel, $n=2513$ ) groups; the $\mathrm{SvO}_{2}-\mathrm{SaO}_{2}$ relationship was distinctly different between groups, as shown by fitted fractional polynomial equations. The $\mathrm{SvO}_{2}$ peaked at $\mathrm{SaO}_{2}$ of $77 \%$ in control patients, but continuously increased as $\mathrm{SaO}_{2}$ increased in phenoxybenzamine patients.

TABLE 2. Venous saturation at intervals of arterial saturation, and effect of phenoxybenzamine*

\begin{tabular}{llclc}
\hline $\mathbf{S a O}_{\mathbf{2}}$ range & \multicolumn{1}{c}{ Control } & Phenoxybenzamine & Difference & \multicolumn{1}{c}{$\boldsymbol{P}$ value } \\
\hline$<65 \%$ & $40.0 \pm 9.2(36.4-43.7)$ & $40.9 \pm 9.0(38.7-43.2)$ & $0.9(-5.0-6.8)$ & $\mathrm{ns}$ \\
$65-70 \%$ & $41.5 \pm 12.5(38.5-44.3)$ & $46.6 \pm 8.7(45.2-47.9)$ & $5.1(0.9-19.4)$ & $<.1(2.7-7.5)$ \\
$71-75 \%$ & $46.4 \pm 12.3(44.8-48.1)$ & $51.5 \pm 7.4(50.8-52.3)$ & $5.5(3.1-17.7)$ & $<0.0001$ \\
$76-80 \%$ & $50.6 \pm 11.9(48.9-52.5)$ & $56.1 \pm 7.7(55.6-56.6)$ & $12.9(9.6-16.2)$ & $<0.0001$ \\
$81-85 \%$ & $46.6 \pm 9.3(43.9-49.3)$ & $59.5 \pm 8.2(58.9-60.1)$ & $25.4(19.2-31.6)$ & 0.0194 \\
$>85 \%$ & $40.2 \pm 7.3(35.2-45.2)$ & $65.6 \pm 9.1(64.4-66.8)$ & 0.0035 \\
\hline
\end{tabular}

Data are mean, standard deviation, and $95 \%$ confidence intervals for $\mathrm{SvO}_{2}$ at intervals of $\mathrm{SaO}_{2}$. The $\mathrm{SvO}_{2}$ peaked with $\mathrm{SaO}_{2}$ in the $76 \%$ to $80 \%$ range in control patients, but continued to increase at higher $\mathrm{SaO}_{2}$ in patients receiving phenoxybenzamine. Differences were tested by the Tukey WSD method after 2-way repeated-measures analysis of variance. There was a progressive increase in the difference between groups as $\mathrm{SaO}_{2}$ increased $(P<.0001$ by test for trend).

polynomial regression models were fit for each group. The data were subsequently partitioned into 6 equal-width strata of $\mathrm{SaO}_{2}$ values from $65 \%$ to $90 \%$ for quantitative analysis. A 2-way repeated-measures analysis of variance (ANOVA) model was used to test for differences in hemodynamic parameters across intervals of $\mathrm{SaO}_{2}$, to test for the effect of phenoxybenzamine, and for the interaction of phenoxybenzamine on the $\mathrm{SaO}_{2}$ effect. Potential confounding differences in other vasoactive drug doses, $\mathrm{FIO}_{2}$, and shunt size, were addressed by entry of these parameters into the model as noninteracting covariates. Post-hoc tests of differences at high $\mathrm{SaO}_{2}$ were performed with Tukey's wholly significant difference (WSD) correction for multiple comparisons, with significance cutoff at $P<.05$ after correction. All analysis was performed with Stata statistical software (StataCorp, College Station, Tex).

\section{Results}

Data from 71 patients comprising 2820 patient-hours (mean 40, median 47, range 6 to 48 hours/patient) were analyzed. There were no significant demographic differences between patients managed with phenoxybenzamine $(n=62)$ or without ( $\mathrm{n}=9$; Table 1). Two patients were placed on ECMO support within the first 48 hours for $\mathrm{SvO}_{2}$ below $25 \%$, metabolic acidosis, and impending cardiovascular collapse, one of whom survived; the overall hospital survival for patients in this study was 68 of 71 or $95.7 \%$.

The distributions of $\mathrm{SvO}_{2}$ and $\mathrm{SaO}_{2}$ reveal a distinct tail at the lower range for $\mathrm{SvO}_{2}$ (Figure 1). Variation in $\mathrm{SvO}_{2}$ 


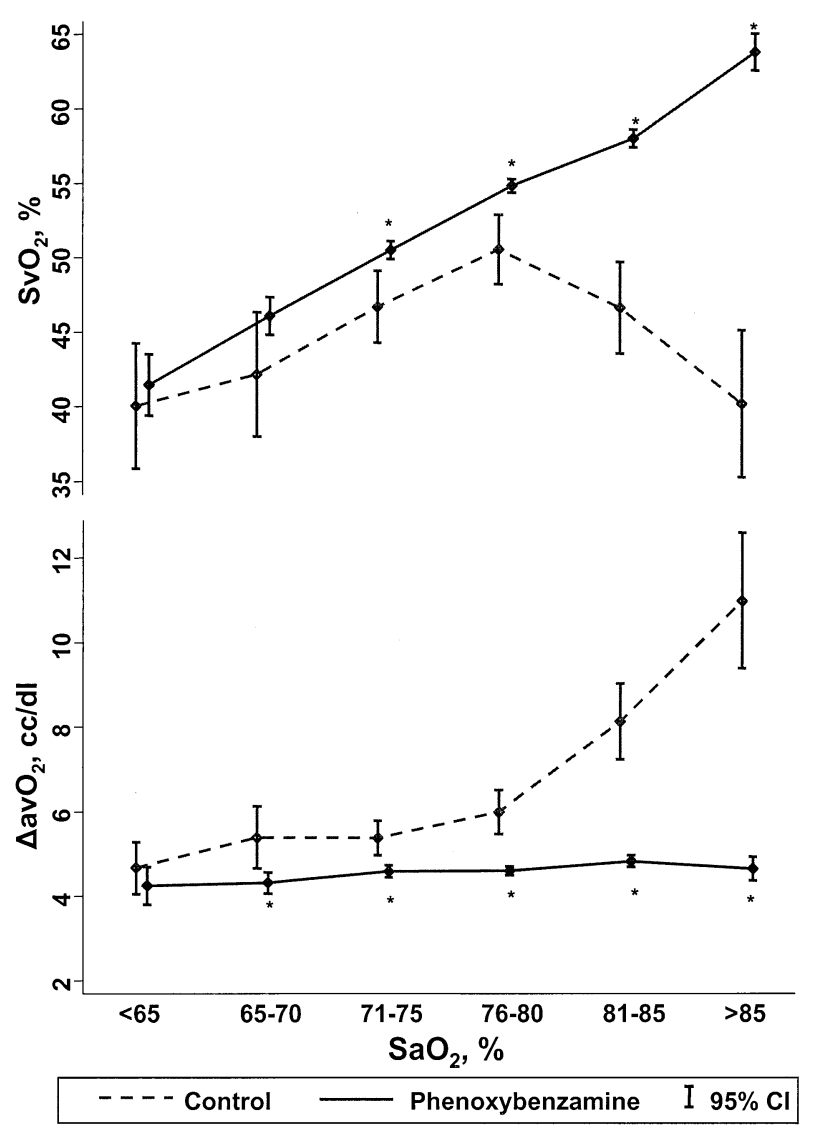

Figure 3. The means and $95 \%$ confidence intervals (CI) of $\mathrm{SvO}_{2}$ and $\triangle \mathrm{Ca}-\mathrm{vO}_{2}$ at intervals of $\mathrm{SaO}_{2}$ is shown for control and phenoxybenzamine groups. The $\mathrm{SvO}_{2}$ was higher with phenoxybenzamine across the whole range $(P<.02)$; the $\mathrm{SaO}_{2}$ effect was highly significant $(P<.0001)$. The $\Delta \mathrm{Ca}-\mathrm{vO}_{2}$ was lower with phenoxybenzamine across the whole range $(P<.001)$; the $\mathrm{SaO}_{2}$ effect was highly significant $(P<.0001)$. With phenoxybenzamine, the $\Delta \mathrm{Ca}-\mathrm{vO}_{2}$ did not vary with $\mathrm{SaO}_{2}(P=$ not significant). Significance was assessed by 2-way repeated measures analysis of variance with adjustment for differences in hemoglobin, $\mathrm{F}_{10}$, $\mathrm{PaCO}_{2}$, shunt size, and doses of dopamine, milrinone, epinephrine, norepinephrine, and nitroprusside as covariates. Significant differences between groups by Tukey WSD post-tests at each $\mathrm{SaO}_{2}$ interval are signified by *.

was much greater than in $\mathrm{SaO}_{2}$ (SD 10.7 vs 5.5, $P<.0001$ ). Despite management directed at maintaining $\mathrm{SvO}_{2}$ greater than $50 \%$, actual $\mathrm{SvO}_{2}$ was less than the target for $758 / 2820$ hours or $26.8 \%$ of the time, and was less than the reported anaerobic threshold of $30 \%{ }^{13}$ for 52 of 2820 hours or $1.8 \%$ of the time. For the 2768 hours without profound venous desaturation, the $\mathrm{SaO}_{2}$ was out of the usual target range of $70 \%$ to $85 \%$ for 374 hours or $13.5 \%$ of the time. During the periods of hemodynamic deterioration and anaerobic risk, the $\mathrm{SaO}_{2}$ was in the target range of $70 \%$ to $85 \%$ for 27 of 52 hours or $52 \%$ of the time. Thus, detection of hemodynamic risk by high or low $\mathrm{SaO}_{2}$ was poor, with a sensitivity of $48 \%$, specificity of $84 \%$, and positive predictive value of only $5 \%$.

The fitted fractional polynomial regressions between $\mathrm{SvO}_{2}$ and $\mathrm{SaO}_{2}$ showed distinctly different patterns in the control and phenoxybenzamine groups:

$$
\begin{gathered}
\text { control: } \mathrm{SvO}_{2}=49-0.064 \cdot\left(77-\mathrm{SaO}_{2}\right)^{2} \\
\qquad R^{2}=0.21, \mathrm{P}<.0001 \\
\text { phenoxybenzamine: } \mathrm{SvO} \mathrm{O}_{2}=0.94 \cdot \mathrm{SaO}_{2}-17 \\
R^{2}=0.32, P<.0001
\end{gathered}
$$

In control patients, the $\mathrm{SvO}_{2}-\mathrm{SaO}_{2}$ relationship showed reduction of $\mathrm{SvO}_{2}$ at both high and low $\mathrm{SaO}_{2}$, with a peak at $\mathrm{SaO}_{2}$ of $77 \%$, in an inverse-square pattern. In patients receiving phenoxybenzamine, the relationship between $\mathrm{SvO}_{2}$ and $\mathrm{SaO}_{2}$ was continuously and linearly positive over the range of $\mathrm{SaO}_{2}$ from $60 \%$ to $90 \%$. The mean predictive error was greater in control than phenoxybenzamine groups $( \pm 11.5 \%$ vs $\pm 8.3 \%, P<.001)$. The actual data and fitted equations are shown in Figure 2.

The $\mathrm{SaO}_{2}-\mathrm{SvO}_{2}$ relationship was quantitatively assessed (Table 2). In control patients, this relationship was in fact convex, with maximal $\mathrm{SvO}_{2}$ occurring at an $\mathrm{SaO}_{2}$ of $75 \%$ to $80 \%$, and with reduced $\mathrm{SvO}_{2}$ at $\mathrm{SaO}_{2}>85 \%$ and $\mathrm{SaO}_{2}<$ $70 \%(P<.01)$, while in patients receiving phenoxybenzamine, the $\mathrm{SvO}_{2}$ increased linearly with $\mathrm{SaO}_{2}>65 \%(P<$ .001 ; Figure 3). In control patients, $\Delta \mathrm{Ca}-\mathrm{vO}_{2}$ increased with $\mathrm{SaO}_{2}>80 \%(P<.001)$, while in patients receiving phenoxybenzamine, $\Delta \mathrm{Ca}-\mathrm{vO}_{2}$ was constant at all $\mathrm{SaO}_{2}(P=$ not significant; Figure 3). The $\mathrm{SvO}_{2}$ was higher, and the $\Delta \mathrm{Ca}-\mathrm{vO}_{2}$ lower, across the whole $\mathrm{SaO}_{2}$ range with phenoxybenzamine $(P<.0001)$, and the difference in $\mathrm{SvO}_{2}$ between groups increased progressively as $\mathrm{SaO}_{2}$ increased $(P<.0001$ by test for trend).

Hemodynamic indices and treatments are summarized in Table 3. SVR was lower in the phenoxybenzamine group, despite higher nitroprusside doses in the control group and higher norepinephrine doses in the phenoxybenzamine group. Most hemodynamic parameters showed significant variation across intervals of $\mathrm{SaO}_{2}$, and differences between treatment groups at high $\mathrm{SaO}_{2}$ were significant for $\mathrm{SvO}_{2}$ $(P<.0005)$, MAP $(P<.0005)$, Qp/Qs $(P<.0005)$, SVRI $(P<.0005)$, PVRI $(P<.0005)$, and indices of oxygen delivery $(P<.005)$. Patients receiving phenoxybenzamine had preservation of systemic oxygen delivery at high $\mathrm{SaO}_{2}$ by stabilization of SVRI, resulting in more balanced Qp/Qs, and a stable reduction in MAP (Figure 4).

\section{Discussion}

The relationship between $\mathrm{SaO}_{2}$ and $\mathrm{SvO}_{2}$ is a complex function of total cardiac output, $\mathrm{Qp} / \mathrm{Qs}$, hematocrit, pulmo- 
TABLE 3. Average 48 hour hemodynamic indices and support: Effects of arterial saturation and phenoxybenzamine

\begin{tabular}{|c|c|c|c|c|c|}
\hline \multirow[b]{2}{*}{ Parameter } & \multicolumn{2}{|c|}{ Treatment group } & \multicolumn{2}{|c|}{ ANOVA factors } & \multirow{2}{*}{$\begin{array}{c}\text { Post-test } \\
\text { Difference at } \\
\mathrm{SaO}_{2}>80 \%\end{array}$} \\
\hline & $\begin{array}{l}\text { Control } \\
(\mathrm{n}=9)\end{array}$ & $\begin{array}{l}\text { Phenoxybenzamine } \\
\qquad(\mathrm{n}=62)\end{array}$ & Phenoxybenzamine & $\begin{array}{c}\mathrm{SaO}_{2} \\
\text { interval }\end{array}$ & \\
\hline $\mathrm{FlO}_{2}$ & $0.41 \pm 0.14(0.33-0.50)$ & $0.36 \pm 0.12(0.33-0.39)$ & & & * \\
\hline $\mathrm{PaCO}_{2}(\mathrm{~mm} \mathrm{Hg})$ & $39.3 \pm 7.7(36-42)$ & $41.9 \pm 6.9(41-43)$ & & & * \\
\hline Hemoglobin (gm/dL) & $16.0 \pm 2.0(15.2-16.9)$ & $15.1 \pm 1.5(14.8-15.4)$ & * & & $\ddagger$ \\
\hline $\mathrm{SaO}_{2}(\%)$ & $75.3 \pm 5.7(72-79)$ & $78.2 \pm 5.4(77-79)$ & & $\ddagger$ & $\ddagger$ \\
\hline Heart rate $\left(\min ^{-1}\right)$ & $175 \pm 16.6(164-186)$ & $169 \pm 17.7(165-173)$ & & & \\
\hline Right atrial pressure, mean $(\mathrm{mm} \mathrm{Hg})$ & $10.4 \pm 1.9(8.7-12.1)$ & $10.2 \pm 2.7(9.6-10.7)$ & & & * \\
\hline Systemic pressure, mean $(\mathrm{mm} \mathrm{Hg})$ & $55.4 \pm 6.9(52-58)$ & $51.3 \pm 5.6(50-52)$ & * & & $\ddagger$ \\
\hline $\mathrm{SvO}_{2}(\%)$ & $46.7 \pm 11.9(41-53)$ & $56.2 \pm 9.4(54-58)$ & $\dagger$ & $\ddagger$ & $\ddagger$ \\
\hline Op/Qs & $1.49 \pm 1.0(1.15-1.83)$ & $1.30 \pm 0.7(1.18-1.41)$ & & $\dagger$ & $\ddagger$ \\
\hline$\Delta \mathrm{Sa}-\mathrm{vO}_{2}(\%)$ & $28.6 \pm 12.4(24-33)$ & $22.1 \pm 7.9(20-24)$ & * & $\dagger$ & $\ddagger$ \\
\hline$\Delta \mathrm{Ca}-\mathrm{vO}_{2}(\mathrm{~mL} / \mathrm{dL})$ & $6.1 \pm 2.7(5.1-7.1)$ & $4.5 \pm 1.6(4.1-4.8)$ & $\dagger$ & $\dagger$ & $\ddagger$ \\
\hline $\mathrm{DO}_{2}\left(\mathrm{~mL} \cdot \min ^{-1} \cdot \mathrm{m}^{-2}\right)$ & $38.4 \pm 18.1(27-50)$ & $49.2 \pm 19.0(45-53)$ & & & $\ddagger$ \\
\hline $\mathrm{O}_{2}$ extraction ratio & $0.38 \pm 0.16(0.32-0.44)$ & $0.28 \pm 0.10(0.26-0.31)$ & * & & $\ddagger$ \\
\hline Os $\left(\mathrm{L} \cdot \mathrm{min}^{-1} \cdot \mathrm{m}^{-2}\right)$ & $3.19 \pm 1.45(2.26-4.12)$ & $4.21 \pm 1.66(3.89-4.54)$ & * & * & $\dagger$ \\
\hline $\mathrm{Op}_{\mathrm{p}}\left(\mathrm{L} \cdot \mathrm{min}^{-1} \cdot \mathrm{m}^{-2}\right)$ & $3.72 \pm 1.09(2.77-4.68)$ & $4.72 \pm 1.72(4.40-5.06)$ & & $\ddagger$ & * \\
\hline SVRI (Wood units) & $17.7 \pm 9.7(15.0-20.5)$ & $11.3 \pm 4.2(10.3-12.2)$ & $\ddagger$ & * & $\ddagger$ \\
\hline PVRI (Wood units) & $12.8 \pm 3.4(11.1-14.5)$ & $9.6 \pm 2.9(9.0-10.2)$ & $\dagger$ & $\ddagger$ & * \\
\hline Dopamine $\left(\mu \mathrm{g} \cdot \mathrm{kg}^{-1} \cdot \min ^{-1}\right)$ & $5.2 \pm 3.0(4.2-6.2)$ & $3.2 \pm 1.2(2.9-3.6)$ & * & & \\
\hline Milrinone $\left(\mu \mathrm{g} \cdot \mathrm{kg}^{-1} \cdot \mathrm{min}^{-1}\right)$ & $0.57 \pm 0.18(0.44-0.69)$ & $0.57 \pm 0.22(0.52-0.61)$ & & & * \\
\hline Epinephrine $\left(\mu \mathrm{g} \cdot \mathrm{kg}^{-1} \cdot \min ^{-1}\right)$ & $0.14 \pm 0.13(0.10-0.20)$ & $0.07 \pm 0.08(0.05-0.09)$ & * & & $\ddagger$ \\
\hline Norepinephrine $\left(\mu \mathrm{g} \cdot \mathrm{kg}^{-1} \cdot \min ^{-1}\right)$ & $0.0 \pm 0.0(0.0)$ & $0.05 \pm 0.09(0.03-0.07)$ & * & & * \\
\hline Nitroprusside $\left(\mu \mathrm{g} \cdot \mathrm{kg}^{-1} \cdot \min ^{-1}\right)$ & $0.95 \pm 0.95(0.43-1.46)$ & $0.27 \pm 0.73(0.08-0.45)$ & * & & * \\
\hline POB total dose $(\mathrm{mg} / \mathrm{kg})$ & $0.0 \pm 0.0(0.0)$ & $0.37 \pm 0.12(0.34-0.39)$ & $\ddagger$ & & \\
\hline
\end{tabular}

Data are expressed as mean \pm standard deviation and (95\% confidence intervals). Results of a nested, repeated-measures analysis of variance model (significance of the main effects phenoxybenzamine and $\mathrm{SaO}_{2}$ interval, and difference between treatment groups at $\mathrm{SaO}_{2} \geq 80 \%$ as post-test) for each parameter are presented as ${ }^{*} \mathrm{P}<.05 ; \uparrow P<.005 ; \ddagger P<.0005$. $\mathrm{FlO}_{2}$, Fraction concentration of inspired oxygen; $\mathrm{PaCO}_{2}$, arterial partial pressure of carbon dioxide; $Q p / Q s$, pulmonary/systemic flow ratio; $\Delta \mathrm{Ca}-\mathrm{vO}_{2}$, arteriovenous oxygen content difference; $\Delta \mathrm{Sa}-\mathrm{vO}_{2}$, arteriovenous oxygen saturation difference; $\mathrm{DO}_{2}$, systemic oxygen delivery; 0 s, systemic blood flow; $Q p$, pulmonary blood flow; SVRI, systemic vascular resistance index; PVRI, pulmonary vascular resistance index.

nary venous saturation, and oxygen consumption. The data provide direct, clinical evidence to validate theoretical models of the critical Qp/Qs and cardiac output dependence of patients after the Norwood operation. The occurrence of systemic vasoconstriction in response to falling systemic perfusion, which will only worsen systemic perfusion in patients with ventricular dysfunction and aortopulmonary runoff, was evident at $\mathrm{SaO}_{2}$ above $80 \%$ in patients managed without phenoxybenzamine-mediated afterload reduction. This situation has traditionally been managed by manipulation of medical gases to raise PVR and lower SVR, using $\mathrm{SaO}_{2}$ as a rough index of $\mathrm{Qp} / \mathrm{Qs}$ balance. In control patients, our data confirm the hypothetical deterioration of systemic oxygen delivery associated with high $\mathrm{SaO}_{2}$, characterized by a dramatic increase in SVR, reduction in cardiac output, and increase in $\mathrm{Qp} / \mathrm{Qs}$. The reduction in cardiac output exceeded the increase in $\mathrm{SaO}_{2}$ as predicted by modeling, ${ }^{21}$ since indices of systemic oxygen delivery fell. Thus, variable Qp/Qs in control patients resulted in a critical range of $\mathrm{SaO}_{2}$ associated with maximum $\mathrm{SvO}_{2}$.

In contrast, patients receiving afterload reduction with phenoxybenzamine did not demonstrate this hemodynamic deterioration at high $\mathrm{SaO}_{2}$, instead demonstrating a relatively constant arterial pressure, low SVR, and less variability in $\mathrm{Qp} / \mathrm{Qs}$. The hemodynamics in patients receiving phenoxybenzamine tended to behave as predicted by models with constant $\mathrm{Qp} / \mathrm{Qs}$ and a variable total cardiac output, with both $\mathrm{SaO}_{2}$ and $\mathrm{SvO}_{2}$ increasing with cardiac output. The clinical effect was that $\mathrm{SaO}_{2}$ as high as $90 \%$ was not associated with deterioration in $\mathrm{SvO}_{2}$. Thus, high $\mathrm{SaO}_{2}$ resulted, not from high Qp/Qs but from higher cardiac output, in the phenoxybenzamine group. The increasing difference between groups at increasing $\mathrm{SaO}_{2}$ provides strong evidence for a fundamental alteration in the circulatory determinants of $\mathrm{SaO}_{2}$ and $\mathrm{SvO}_{2}$.

Errors in derived indices such as Qp/Qs and SVRI may result from the limitations imposed by assumptions of pulmonary vein saturation ${ }^{15}$ and oxygen consumption. ${ }^{17,18} \mathrm{We}$ specifically did not wean $\mathrm{FIO}_{2}$ to limit $\mathrm{SaO}_{2}$ and would attempt to reduce work of breathing in unparalyzed patients with low $\mathrm{SvO}_{2}$ by sedation and ventilator adjustment. No further benefit of pharmacologic paralysis on oxygen consumption has been demonstrated, ${ }^{19}$ and no systematic deviations in this clinical approach were evident between 


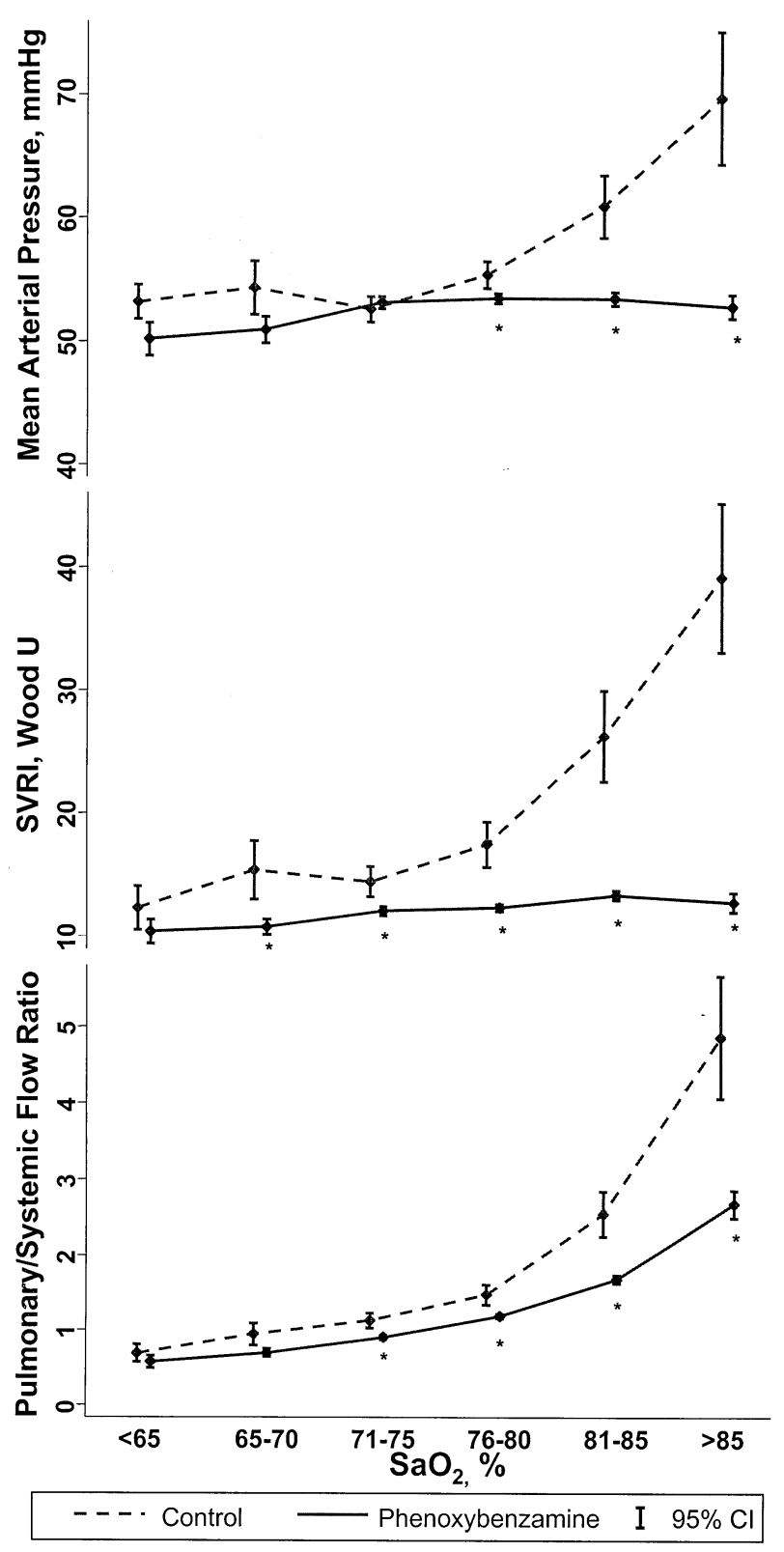

Figure 4. The means and $95 \%$ confidence intervals of MAP, $0 \mathrm{p} /$ Qs, and SVRI at intervals of $\mathrm{SaO}_{2}$ in control and phenoxybenzamine groups. The MAP, $\mathrm{Qp} / \mathrm{Qs}$, and SVRI were lower with phenoxybenzamine across the whole range $(P<.001)$; the $\mathrm{SaO}_{2}$ effect was highly significant $(P<.0001)$. Significant differences between groups by Tukey WSD after 2-way repeated measures analysis of variance at each $\mathrm{SaO}_{2}$ interval are indicated by *.

groups. Neither of these factors would change the primary finding of the alteration $\mathrm{SaO}_{2}-\mathrm{SvO}_{2}$ relationship by phenoxybenzamine.

Although the analysis of clinical data in this study is unique, the early patients in this study have been the subjects of prior investigation. ${ }^{12,13}$ Differential expansion of the size of the treatment group has occurred because we have since administered phenoxybenzamine for all Norwood procedures, except for 2 patients without parental consent for phenoxybenzamine; the resulting imbalance in group size would only reduce the power to detect a statistically significant pharmacologic effect. Because phenoxybenzamine was administered without randomization, the differences between treatment groups could result from existing differences in integrated cardiovascular reflex responses or in treatment variables between patients. However, the groups were highly similar in all factors except for the use of phenoxybenzamine, and the different patterns of response persisted after controlling for differences in other treatment variables.

With continuous recordings of oximetric $\mathrm{SvO}_{2}$ in the acute postoperative period, we have demonstrated rapid deterioration in $\mathrm{SvO}_{2}$ associated with systemic vasoconstriction in patients not receiving phenoxybenzamine. ${ }^{12}$ Since norepinephrine is the postganglionic sympathetic neurotransmitter, $\alpha$-adrenergic blockade would be expected to blunt the profound sympathetic vasomotor responses observed in high-risk neonates undergoing complex cardiovascular procedures. ${ }^{14}$ Although other drugs may be as effective as phenoxybenzamine in reducing SVR under resting conditions, we did not achieve similar results in the control group with routine use of milrinone and sodium nitroprusside.

The perioperative medical management of these patients requires synthesis of information from multiple sources to derive management decisions, which may involve compromise between competing goals. Our vasoactive drug strategy used milrinone for post- $\beta$ receptor amplification of inotropy and vasodilation, and dopamine for dopaminergic effects only. A fixed dose of phenoxybenzamine was administered on CPB to all patients in the phenoxybenzamine group to block $\alpha$-adrenergic vasoconstriction, and titration of short-acting drugs to modify SVR was necessary. We used epinephrine and norepinephrine liberally to modify SVR and to provide potent inotropy, and occasionally added low-dose nitroprusside for additional vasodilation. We added an infusion of phenoxybenzamine in 46 of 62 patients in the phenoxybenzamine group if the postoperative hemodynamic pattern showed a need for more consistent SVR reduction. Through multiple stepwise manipulations, the medication mixture could become complex in some patients, and this study did not specifically address strategies to simplify vasoactive drug use. However, our data suggest that $\alpha$-adrenergic blockade is a more effective approach to modify the intense sympathetically mediated vasomotor responses in these infants, and the use of a very long-acting drug like phenoxybenzamine commits the patient to a treatment strategy based on sustained SVR reduction. Optimization of hemodynamics by control of SVR, as predicted in 
a mathematical model of post-Norwood circulation, ${ }^{22}$ was confirmed by our data.

The data also provide direct evidence of the poor predictive value of $\mathrm{SaO}_{2}$ for systemic oxygen delivery, as predicted from theoretical models, ${ }^{11,21-23}$ and emphasizing the importance of continuous $\mathrm{SvO}_{2}$ monitoring ${ }^{11-13}$ to indicate systemic oxygen status. A priori, we did not anticipate any predictable relationship between $\mathrm{SaO}_{2}$ and $\mathrm{SvO}_{2}$; instead, we relied on continuous $\mathrm{SvO}_{2}$ measurement to guide management aimed at provision of adequate oxygen delivery. Even in the phenoxybenzamine group, only $32 \%$ of the $\mathrm{SvO}_{2}$ variance could be explained by $\mathrm{SaO}_{2}$; therefore, we do not advocate acute postoperative management of these patients without $\mathrm{SvO}_{2}$ monitoring.

The findings of the current study support management strategies based on the measurement and maximization of $\mathrm{SvO}_{2}$, given the poor predictive value of $\mathrm{SaO}_{2}$ for $\mathrm{SvO}_{2}$. The data provide support both for management strategies such as intentional hypercapnia ${ }^{24}$ to raise PVR when SVR is relatively uncontrolled, and for pharmacologic control of SVR with phenoxybenzamine. With the latter strategy, higher $\mathrm{SaO}_{2}$ is not deleterious, and is typically associated with improved systemic oxygen delivery.

\section{References}

1. Wernovsky G, Bove EL. Single ventricle lesions. In: Chang AC, Hanley FL, Wernovsky G, Wessel DL, Eds., Pediatric cardiac intensive care. Baltimore: Lippincott Williams \& Wilkins; 1998. pp. 27187.

2. Nicholson SC, Steven JM, Jobes DR. Hypoplastic left heart syndrome. In: Nichols DG, Cameron DE, Greeley WJ, Lappe DG, Ungerleider RM, Wetzel RC, Eds., Critical Heart Disease in Infants and Children. St Louis: Mosby; 1995. pp. 863-84.

3. Rossi AF, Sommer RJ, Lotvin A, et al. Usefulness of intermittent monitoring of mixed venous oxygen saturation after stage I palliation for hypoplastic left heart syndrome. Am J Cardiol. 1994;73:1118-23.

4. Riordan CJ, Locher JP, Santamore WP, Villafane J, Austin EH. Monitoring systemic venous oxygen saturation in the hypoplastic left heart syndrome. Ann Thorac Surg. 1997;63:835-7.

5. Jacobs ML, Norwood WI. Hypoplastic left heart syndrome. In: Jacobs ML, Norwood WI, Eds., Pediatric cardiac surgery: Current Issues. Stoneham, MA: Butterworth-Heinmann; 1992. pp. 182-92.

6. Barnea O, Santamore WP, Rossi A, Salloum E, Chien S, Austin EH. Estimation of oxygen delivery in newborns with a univentricular circulation. Circulation. 1998;98:1407.

7. Jobes DR, Nicolson SC, Steven JM, Miller M, Jacobs ML, Norwood WI. Carbon dioxide prevents pulmonary overcirculation in hypoplastic left heart syndrome. Ann Thorac Surg. 1992;54:150-1.
8. Mora GA, Pizarro C, Jacobs ML, Norwood WI. Experimental model of single ventricle. Influence of carbon dioxide on pulmonary vascular dynamics. Circulation. 1994;90:1143-6.

9. Shime N, Hashimoto S, Hiramatsu N, Oka T, Kageyama K, Tanaka Y. Hypoxic gas therapy using nitrogen in the preoperative management of neonates with hypoplastic left heart syndrome. Pediatr Crit Care Med. 2000;1:38-41.

10. Day RW, Tani LY, Minich L, et al. Congenitial heart disease with ductal-dependent systemic perfusion: Doppler ultrasonography flow velocities are altered by changes in the fraction of inspired oxygen. J Heart Lung Transplant. 1995;14:718-25.

11. Tweddell JS, Hoffman GM. Postoperative management in patients with complex congenital heart disease. Semin Thorac Cardiovasc Surg Pediatr Card Surg Annu. 2002;5(1):187-205.

12. Tweddell JS, Hoffman GM, Fedderly RT, et al. Phenoxybenzamine improves systemic oxygen delivery following the Norwood procedure. Ann Thorac Surg. 1999;67:161-8.

13. Hoffman GM, Tweddell JS, Ghanayem NS, et al. Venous saturation and the anaerobic threshold in neonates after the Norwood procedure for hypoplastic left heart syndrome. Ann Thorac Surg. 2000;70:151521.

14. Anand KJS, Hickey PR. Halothane-morphine compared with highdose sufentanil for anesthesia and postoperative analgesia in neonatal cardiac surgery. $N$ Engl J Med. 1992;326:1-9.

15. Taeed R, Schwartz SM, Pearl JM, et al. Unrecognized pulmonary venous desaturation early after Norwood palliation confounds Qp:Qs assessment and compromises oxygen delivery. Circulation. 2001;103: 2699-704.

16. Freed MD, Miettinen OS, Nadas AS. Oximetric detection of intracardiac left-to-right shunts. Br Heart J. 1979;42:690-4.

17. Chang AC, Kulik TJ, Hickey PR, Wessel DL. Real-time gas exchange measurement of oxygen consumption in neonates and infants after cardiac surgery. Crit Care Med. 1993;21:1369-75.

18. Buheitel G, Scharf J, Hofbeck M, Singer H. Estimation of cardiac index by means of the arterial and mixed venous oxygen content and pulmonary oxygen uptake determination in the early post-operative period following surgery of congenital heart disease. Intensive Care Med. 1994;20:500-3.

19. Palmisano BW, Fisher DM, Willis M, Gregory GA, Ebert PA. The effect of paralysis on oxygen consumption in normoxic children after cardiac surgery. Anesthesiology. 1984;61(5):518-22.

20. Cleveland WS. Robust locally weighted regression and smoothing scatterplots. J Am Stat Assoc. 1979;74:829-36.

21. Francis DP, Willson K, Thorne SA, Davies LC, Coats AJS. Oxygenation in patients with a functionally univentricular circulation and complete mixing of blood: are saturation and flow interchangeable? Circulation. 1999;100:2198-203.

22. Migliavacca F, Pennati G, Dubini G, et al. Modeling of the Norwood circulation: effects of shunt size, vascular resistances, and heart rate. Am J Physiol Heart Circ Physiol. 2001;280:H2076-86.

23. Austin EH, Santamore WP, Barnea O. Balancing the circulation in hypoplastic left heart syndrome. J Cardiovasc Surg. 1994;35:137-9.

24. Tabbutt S, Ramamoorthy C, Montenegrro LM, Durning SM, Kurth $\mathrm{CD}$, Steven JM, et al. Impact of inspired gas mixtures on preoperative infants with hypoplastic left heart syndrome during controlled ventilation. Circulation. 2001;104(suppl 1):I159-I164. 